\title{
Three-parameter-based streamflow elasticity model: application to MOPEX basins in the USA at annual and seasonal scales
}

\author{
Goutam Konapala and Ashok K. Mishra \\ Glenn Department of Civil Engineering, Clemson University, Clemson, SC, USA \\ Correspondence to: Ashok K. Mishra (ashokm@g.clemson.edu) \\ Received: 31 December 2015 - Published in Hydrol. Earth Syst. Sci. Discuss.: 16 February 2016 \\ Accepted: 24 May 2016 - Published: 1 July 2016
}

\begin{abstract}
We present a three-parameter streamflow elasticity model as a function of precipitation, potential evaporation, and change in groundwater storage applicable at both seasonal and annual scales. The model was applied to 245 Model Parameter Estimation Experiment (MOPEX) basins spread across the continental USA. The analysis of the modified equation at annual and seasonal scales indicated that the groundwater and surface water storage change contributes significantly to the streamflow elasticity. Overall, in case of annual as well as seasonal water balances, precipitation has higher elasticity values when compared to both potential evapotranspiration and storage changes. The streamflow elasticities show significant nonlinear associations with the climate conditions of the catchments indicating a complex interplay between elasticities and climate variables with substantial seasonal variations.
\end{abstract}

\section{Introduction}

Several studies have emphasized on the sensitivity of streamflow to fluctuations in climate for river basins across the world. Many studies used atmospheric forcings as an input to a hydrologic model to quantify the resulting changes in streamflow. For example, hydrologic models like the Sacramento model (Němec and Schaake, 1982), abcd model (Sankarasubramanian et al., 2001), SIMHYD and AWBM models (Chiew, 2006) were applied to evaluate the influence of various climate variables on streamflow. Another popular approach involves analytically deriving the sensitivity of streamflow based on various conceptual models. For example, Schaake (1990) first formulated the stream- flow elasticity due to precipitation only. Later, Dooge (1992) devised a method to quantify sensitivity of streamflow to both precipitation and potential evapotranspiration (PET). Arora (2002) extended this work of assessing streamflow sensitivities to PET and $P$ utilizing general circulation model (GCM) data. He derived the streamflow sensitivities to PET and $P$ by using five different empirical formulae, namely the Schreiber equation (Schreiber, 1904), the Ol'dekop equation (Ol'dekop, 1911), the Budyko equation (Budyko, 1961. ), the Turc-Pike equation (Pike, 1964; Turc, 1954), and the Zhang et al. equation (2001). More recently, Yang and Yang (2011) derived streamflow sensitivities to various climatic variables by combining an analytical solution of the Budyko hypothesis and differential form of the Penman equation. Multivariate statistical methods are used to estimate the relationship between climate variables and streamflow at a particular site. For example, a bivariate linear regression method based on precipitation and temperature anomalies (Potter et al., 2011) and a bivariate generalized linear regression method based on precipitation and potential evapotranspiration anomalies (Andréassian et al., 2015) were applied for determining the streamflow sensitivities.

The sensitivity of the streamflow is usually expressed in terms of a nondimensional quantity called elasticity where a positive elasticity value indicates an increase in streamflow with increase in the climate variable, whereas a negative elasticity value indicates a decrease in streamflow with an increase in the climate variable (Sankarasubramanian et al. 2001; Potter et al., 2011). Hence, climate elasticities link the climate factors to variations of streamflow. Most of the annual elasticity-based model studies point to a common conclusion of higher precipitation influence on streamflow when 
compared to other climate variables like PET, temperature, wind speed, etc. Fu et al. (2007) indicated that in locations with low temperatures, the streamflow elasticity to precipitation is higher than locations with higher temperatures. Yang and Yang (2011) has identified positive and negative streamflow elasticity due to relative humidity and wind speed, respectively. More recently, Andréassian et al. (2015) has identified a negative elasticity due to potential evapotranspiration.

Most of the elasticity models are applied at annual scales, however, the dominant control of climatic and landscape properties on hydrologic responses are timescale dependent (Atkinson et al., 2002; Farmer et al., 2003; Wang and Alimohammadi, 2011). Estimating this seasonal control of climate on streamflow can be beneficial to water resources' managers and planners. The water availability and demand change across each season and as a water resource manager or planner, it is very important to balance these needs by constructing storage facilities or by implementing efficient water conservation practices. However, before implementing these strategies, we first need to understand how different climate factors affect streamflow at seasonal scales in conjunction. In this direction, previous studies (Vano et al., 2014; Guo et al., 2008; Berghuijs et al., 2014, 2016; Chen et al., 2013; Istanbulluoglu et al., 2012; Jiang et al., 2015; Ye et al., 2015) have investigated water balance dynamics by considering seasonality, storage change, and extremes. However, these studies have not investigated the combined effect of various climate factors on streamflow at a seasonal scale. A conjunct analysis would likely provide a more robust solution by considering the coevolution of elasticities and climate variables. As discussed above, climate elasticity provides an easy way to integrate the effects of various climate factors on streamflow without directly considering the effects of soil, land cover, etc. For example, a positive precipitation elasticity value of 2 indicates a $2 \%$ increase of streamflow with $1 \%$ increase in precipitation, whereas a negative storage change elasticity value of 2 indicates a $2 \%$ decrease in streamflow with $1 \%$ increase in groundwater storage. Further, several studied have explored the relationship between mean annual catchment properties and the elasticities (Sankarasubramanium et al., 2001; Chiew, 2006; Fu et al., 2011). A similar exploration extended to seasonal scale would further assist the planners to create a catchment scale strategy for efficient management of seasonal water resources. Hence, a natural extension of this climate elasticity framework to a seasonal scale would serve our purpose of understanding the seasonal climate and physical controls on water resource availability.

Usually, most of the climate elasticity models assume that at annual scale both water storage change and groundwater loss are insignificant (Yang and Yang, 2011; Arora 2002). This assumption leads to a simplified water balance equation, which represents precipitation as a sum of evapotranspiration and streamflow. However, this assumption holds true only if the deep groundwater storage is negligible over the considered time period for annual studies (Wang, 2014; Tomer and Schilling, 2009). Therefore, we also check the validity of this assumption by including a term of ground and soil water storage at annual scale. Similarly, on a seasonal scale these changes also cannot be neglected. Hence, the purpose of the article is threefold: (a) to test the performance of the elasticity model at annual scale by incorporating storage change as an influencing component, (b) to evaluate climate elasticities at the seasonal scale, and (c) to explore the relationships between estimated elasticities and catchment properties.

The paper is organized as follows. In Sect. 2, data and methodology are discussed. Section 3 discusses the results by evaluating the modified climate elasticity model at an annual scale by incorporating precipitation, potential evapotranspiration, and change in storage components. Further, we present the streamflow elasticity at a seasonal scale and evaluate their spatial variability. Finally, Sect. 4 presents the conclusions along with the implications of these results.

\section{Data sources and methodology}

\subsection{Data}

The hydrometeorological data (1948-2003) were collected from the Model Parameter Estimation Experiment (MOPEX) basins located in the USA, which are considered to have limited human influence (Schaake et al.,2006) and hence allow this study to focus on seasonal climate controls. In the MOPEX data set, daily precipitation $(P)$ is processed by the NWS Hydrology Laboratory, and streamflow $(Q)$ is obtained from USGS National Water Information System (NWIS). Monthly actual evaporation from 1986 to 2006 was obtained from the data set provided by Zhang et al. (2010) at $0.5^{\circ}$ resolution hosted at the University of Montana website. We selected PET values from climate research unit (CRU) database available at $0.5^{\circ}$ resolution based on an improved PenmanMonteith method (Harris et al., 2014). The actual evaporation and potential evaporation data are temporally averaged to annual scale values for annual analysis and to seasonal scale for seasonal values. Also, the gridded values of actual evapotranspiration (AET) and PET are spatially averaged to the watershed scales for further analysis. This research is focused on the overlapping time period of all the data sets, i.e., 1983-2003. We considered 245 MOPEX basins located in the US since there are no missing data for those regions.

\section{Methodology}

\subsection{Modified streamflow elasticity model applicable at seasonal and annual scales}

Schaake (1990) first derived the relationship between elasticity of runoff $(Q)$ to precipitation $(P)$ as

$$
\varepsilon_{Q / P}=\frac{\Delta Q}{\Delta P} \frac{P}{Q} \text {. }
$$



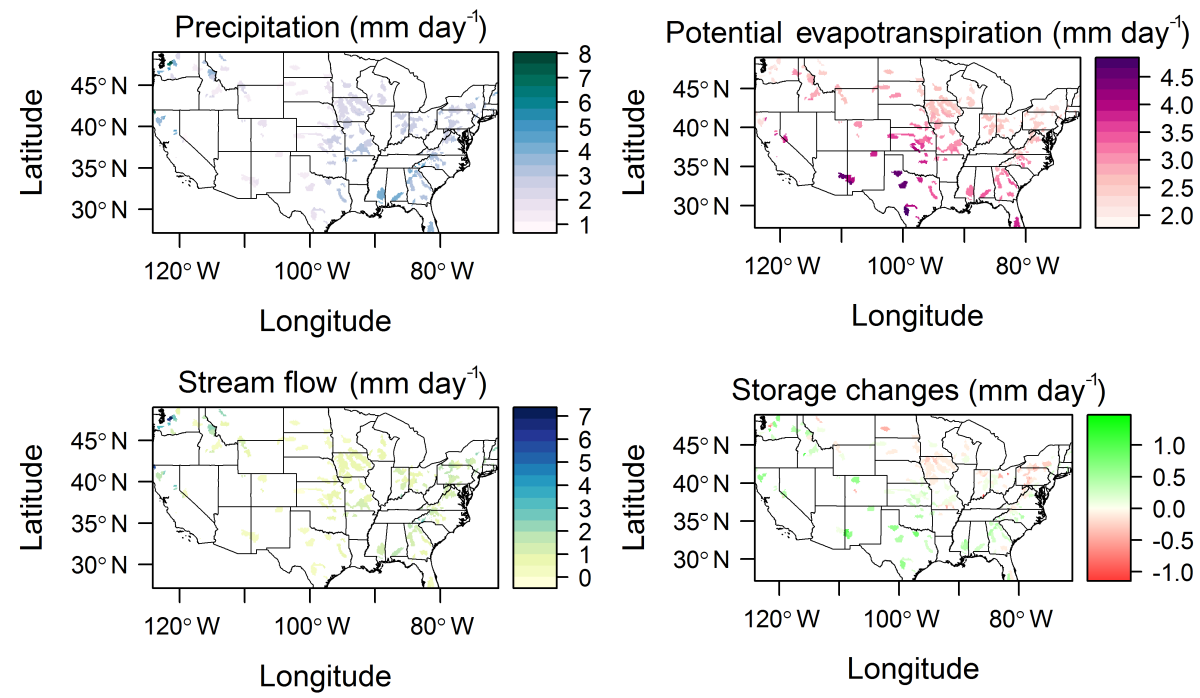

Figure 1. Mean of annual precipitation, potential evapotranspiration, streamflow, and storage changes in millimeters per day from 1983 to 2003.

Later, Arora (2002) proposed the bivariate climate elasticity based on PET and precipitation $(P)$ as expressed in Eq. (2).

$$
\frac{\Delta Q}{Q}=\varepsilon_{\frac{Q}{P}} \frac{\Delta P}{P}+\varepsilon_{\frac{Q}{\mathrm{PET}}} \frac{\Delta \mathrm{PET}}{\mathrm{PET}}
$$

where $\varepsilon \frac{Q}{P}$ and $\varepsilon \frac{Q}{\mathrm{PET}}$ are elasticities due to precipitation and potential evapotranspiration, respectively. Recently, Yang and Yang (2011) extended the bivariate framework (Eq. 2) by replacing the $\triangle$ PET term with the differential model developed by Roderick et al. (2007). This modification will eventually include precipitation $(P)$, temperature $(T)$, net radiation $\left(R_{\mathrm{n}}\right)$, and wind speed $\left(U_{2}\right)$ leading to Eq. (3):

$$
\frac{\Delta Q}{Q}=\varepsilon_{\frac{Q}{P}} \frac{\Delta P}{P}+\varepsilon_{\frac{Q}{T}} \frac{\Delta T}{T}+\varepsilon_{\frac{Q}{R_{\mathrm{n}}}} \frac{\Delta R_{\mathrm{n}}}{R_{\mathrm{n}}}+\varepsilon_{\frac{Q}{U_{2}}} \frac{\Delta U_{2}}{U_{2}} .
$$

We followed a similar approach as the above studies but replaced the model-based results with observational data. Hence, to represent the co-variations of streamflow with precipitation, potential evapotranspiration, and storage change, we formulate a trivariate relationship as illustrated in Eq. (4):

$\frac{Q_{t}-Q}{Q}=\varepsilon_{\frac{Q}{P}} \frac{P_{t}-P}{P}+\varepsilon_{\frac{Q}{\mathrm{PET}}} \frac{\mathrm{PET}_{t}-\mathrm{PET}^{\mathrm{PET}}}{\mathrm{PET}}+\varepsilon_{\frac{Q}{\mathrm{DS}}} \frac{\mathrm{DS}_{t}-\mathrm{DS}}{\mathrm{DS}}$,

where $Q_{t}, P_{t}, \mathrm{PET}_{t}$, and $\mathrm{DS}_{t}$ are streamflow, precipitation, potential evapotranspiration, and storage change. The water storage change was averaged annually (seasonally) for year $t$, respectively, whereas $Q, P$, PET, and DS represent their long-term averages. Storage change $\left(\mathrm{DS}_{t}\right)$ is estimated as residuals of the water balance closure $\left(\mathrm{DS}_{t}=P_{t}\right.$ $\mathrm{AET}_{t}-Q_{t}$ ). Figure 1 shows the MOPEX basins considered in our study and the spatial distribution of the long-term averages of $P, Q$, PET, and DS. The precipitation and streamflow are higher in the northwestern and southwestern regions of the USA, whereas the potential evapotranspiration is higher in the southern part of the USA. The northeastern and central parts witness a decrease in groundwater and surface storage, whereas in other regions it has increased. In situations where the underlying processes are unknown, it is possible to use a statistical model. Hence, a multivariate regression approach was adopted as in Andréassian et al. (2015). The streamflow elasticities $\left(\varepsilon \frac{Q}{P}, \varepsilon \frac{Q}{\mathrm{PET}}\right.$, and $\left.\varepsilon \frac{Q}{\mathrm{DS}}\right)$ were determined by fitting data on annual anomalies using a multiple generalized least square (GLS) regression equation (Johnston, 1972) and model parameters are obtained by the maximum likelihood method. GLS can be used to perform linear regression when there is significant correlation between the explanatory variables used in the regression analysis. In these cases, ordinary least squares or weighted least squares can be statistically inefficient, or even give misleading inferences (Greene, 2008). Here, the GLS model was fitted to 245 selected watersheds with all the values aggregated to annual means. Then, the significance of regression coefficients was evaluated with a bootstrap approach as mentioned in Andréassian et al. (2015) by considering 999 sample parameters with $95 \%$ significance level. We apply Eq. (4) for calculating the seasonal elasticities. In this case, we replaced the annual mean with the seasonal mean by aggregating the data into spring (March-May), summer (June-August), fall (September-November), and winter (December-February) averages. Hence, we obtain statistically significant streamflow elasticities due to precipitation, potential evapotranspiration, and storage change for each season. 


\subsection{Evaluation of performance of the modified climate elasticity model at annual scale}

We evaluated our trivariate elasticity model (Eq. 4) against the bivariate elasticity regression model (Eq. 2) using Akaike information criterion (AIC) (Akiake, 1998) and Bayesian information criterion (BIC) (Schwarz, 1978).

$\mathrm{AIC}$ is given by the following equation as

$\mathrm{AIC}=-2 \sum_{i=1}^{n} \log \left\{g\left(x_{i} \mid \theta_{k}\right)\right\}+2 k$,

where $n$ is the number of observations, $g(x)$ can be either Eq. (4) or Eq. (2) $\theta_{k}$ are the streamflow elasticities of the corresponding models, and $k$ is the number of parameters. In our context, AIC offers a relative estimate of the information lost when the elasticity model is fitted to the data to represent the processes involved. As when building any statistical model, our aim is to model the processes with minimum information loss (better goodness of fit), and the preferred model is the one in which the absolute value of AIC would be minimum. As evident from Eq. (5), we can see that the first term in the equation tends to decrease with the model parameters, whereas the second term increases. Hence, AIC penalizes for the increase in the number of parameters. For example, if model A has an absolute AIC value of 10 and model B has a value of 20 , model A is supposed to lose less information and hence it is the preferred model. Another metric useful for calculating information loss similar to AIC is called Bayesian information criterion (BIC). It is computed using following equation:

$\mathrm{BIC}=-2 \sum_{i=1}^{n} \log \left\{g\left(x_{i} \mid \theta_{k}\right)\right\}+\log (n) k$.

As we can see, the BIC is similar to AIC except that the second term is multiplied by a factor of $0.5 \ln (n)$ with respect to AIC. As a result, BIC leans more towards less parameterized models. Hence, BIC should also be interpreted in a similar way to AIC. The only difference is that BIC gives more weight to the number of parameters in a model and penalizes more for the modified trivariate modeling our context. Overall, the preferred model would be the one which has both minimum $\mathrm{AIC}$ and BIC values.

\subsection{Relationship between elasticity and hydroclimatic characteristics of the catchments}

Previous studies (Sankarasubramanium et al., 2001; Chiew, 2006; Fu et al., 2011) highlighted the nonlinear relation between the annual elasticities and the considered hydroclimatic variables. Expecting a similar behavior at seasonal scale, we quantify the strength of association using both linear and nonlinear association metrics. For the purpose of estimating the linear and nonlinear associations, we considered the seasonal precipitation $(P)$, storage changes (DS), POTENTIAL evapotranspiration (PET), aridity index (AI), and evaporative index (EI). Even though we have estimated the elasticities based on seasonal variations in $P, Q$, and DS, we want to further explore the relationship between seasonal magnitudes of these variables and the calculated elasticities. In addition to that, aridity index (AI) and evaporative index (EI), which are indicators of catchment (climate) and physical characteristics can explore the seasonal control of catchment properties on elasticities. Hence, we aggregate $P, Q$, DS, PET, and AET at seasonal scales and calculate their averages over the study period. Based on these averages, seasonal AI and EI are estimated as PET / $(P-D S)$ and AET / $(P-$ DS), respectively (Chen et al, 2012). We estimated the linear association based on Pearson correlation coefficients and estimated the level of significance based on $p$ values derived from a two-sided permutation test of 999 replicates (Helsel and Hirsch, 1992). Several nonlinear association metrics like mutual information (MI) (Cover and Thomas, 1991), maximal information coefficient (MIC) (Reshef et al., 2011), Hoeffding distance (Hoeffding, 1948), and distance correlation (Szekely and Rizzo, 2009) are prevalent in literature. Among these measures, distance correlation coefficient is easier to implement and has comparatively better statistical power (Kinney and Atwal, 2014), which is used in this study. As this metric is new to the field of hydrology, we provided an overview of distance correlation coefficient as follows.

For computing the distance correlation measure between two random variables $(X, Y)$, we first compute the pairwise distances matrices $\left(\mathbf{a}_{i, j}\right)$ and $\left(b_{i, j}\right)$ as

$\begin{aligned} \mathbf{a}_{i, j} & =\left\|X_{i}-X_{j}\right\| \\ \mathbf{b}_{i, j} & =\left\|Y_{i}-Y_{j}\right\|,\end{aligned}$

where $i, j=1,2,3,4,5, \ldots, n$ and $\|\ldots\|$ denotes the Euclidean (in our case) distance. Now, we center these distances matrices as shown below

$A_{i, j}=a_{i, j}-\bar{a}_{i .}-\bar{a}_{. j}+\bar{a}_{. .}$
$B_{i, j}=b_{i, j}-\bar{b}_{i .}-\bar{b}_{. j}+\bar{b}_{. .}$,

where $\bar{a}_{i .}$ and $\bar{b}_{i .}$ are the $i$ th row means; $\bar{a}_{. j}$ and $\bar{b}_{. j}$ are the $j$ th column means; and $\bar{a}_{. .}$and $\bar{b}_{. .}$are the overall mean of the $\left(\mathbf{a}_{i, j}\right)$ and $\left(\mathbf{b}_{i, j}\right)$ matrices, respectively. Then, we estimate the squared distance covariance as the arithmetic average of the products $A_{i, j}$ and $B_{i, j}$

$\mathrm{dCov}_{n}^{2}(X, Y)=\frac{1}{n^{2}} \sum_{i, j=1}^{n} A_{i, j} \cdot B_{i, j}$.

Similarly, we estimate the distance variance as

$\mathrm{d}_{\operatorname{Var}_{n}^{2}}^{2}(X)=\mathrm{dCov}_{n}^{2}(X, X)=\frac{1}{n^{2}} \sum_{i, j=1}^{n} A_{i, j}^{2}$. 


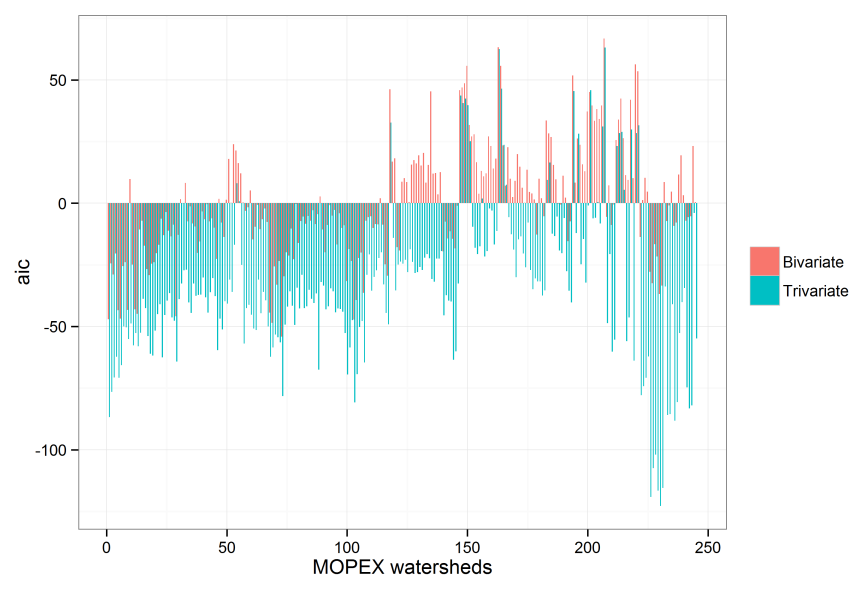

Figure 2. AIC values of the bivariate and trivariate models for the selected MOPEX basins.

Finally, the distance correlation is obtained as

$\mathrm{d} \operatorname{Cor}(X, Y)=\frac{\mathrm{d} \operatorname{Cov}(X, Y)}{\sqrt{\mathrm{d} \operatorname{Var}(X) \times \mathrm{d} \operatorname{Var}(Y)}}$.

The significance of the calculated correlation is estimated by a one-sided permutation test of 999 replicates. In both the linear and nonlinear cases, only the relations which satisfy the $95 \%$ significance level $(p<0.05)$ are presented.

\section{Results and discussion}

The trivariate and bivariate models were applied to 245 watersheds across the continental USA. In this section, we first discuss the validity of the three-parameter elasticity model at an annual scale based on AIC and BIC criterion. Later, we assess how the inclusion of the storage coefficient term has changed the streamflow elasticity of precipitation in the trivariate model compared to the previous elasticity model. Then, we evaluate the change in streamflow elasticity at seasonal scale and explore the various climatic controls on the computed elasticities.

\subsection{Performance of the modified climate elasticity model}

The proposed trivariate model was evaluated against the bivariate model using AIC and BIC. As mentioned earlier, AIC gives the relative quality of a statistical model with the preferred model having the lowest absolute value. Figure 2 gives the AIC values of both the bivariate and trivariate models for each of the 245 watersheds. We can see that in all of the watersheds, AIC values pertaining to the trivariate model are less than their counterparts in the bivariate model. To penalize the added storage coefficient term, we also computed the BIC for both the bivariate and trivariate models for each of the selected watersheds. Figure 3 illustrates the BIC val-

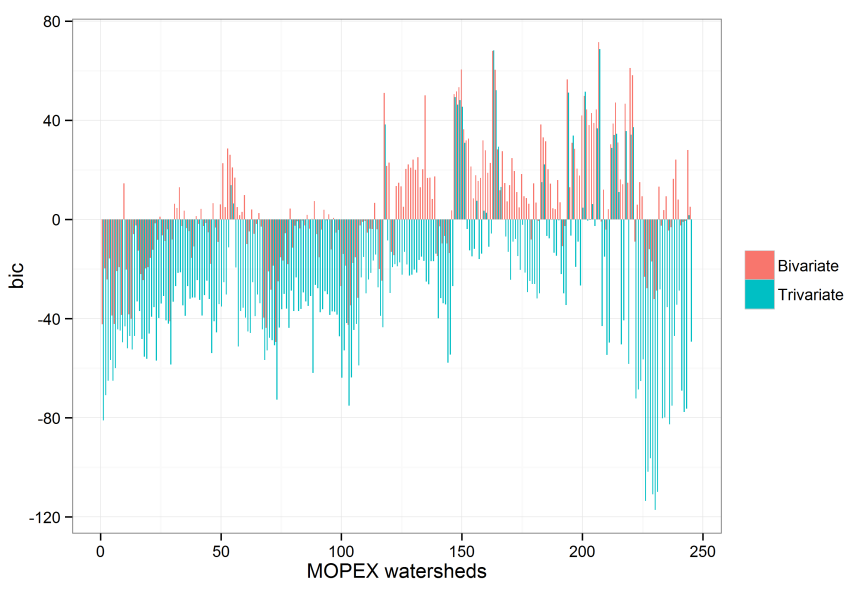

Figure 3. BIC values of the bivariate and trivariate models for the selected MOPEX basins.

ues for these watersheds. This also indicates that BIC values for the trivariate model are less than those for the bivariate model. These results indicate that the proposed trivariate model is obviously a better choice when compared to bivariate model. The BIC result indicates that even if we give more weight to penalize the added term, the modified model performs better than the bivariate method. In addition to that, Fig. 4 highlights the increase in the number of watersheds with the statistically significant streamflow elasticities due to PET in the trivariate equation. We can see that the number of statistically significant streamflow elasticity values due to PET is lesser in number indicating that PET might be a less influential factor to the streamflow variability at some of the selected MOPEX basins. Overall, this increase in number of statistically significant watersheds due to the addition of storage term further suggests that the trivariate model is a better fit than the bivariate model.

\subsection{Changes in annual streamflow elasticity using the trivariate model}

We calculated the difference in streamflow elasticity between the trivariate and bivariate models as $\varepsilon \frac{Q}{P_{\mathrm{Tri}}}-\varepsilon_{\frac{Q}{P_{\mathrm{Bi}}}}$. Figure 5 shows the spatial distribution (left side) of arithmetic differences between trivariate and bivariate streamflow elasticities due to precipitation and its probability distribution based on numerical values obtained from 245 watersheds shown as a violin plot (right side). The differences in elasticity are mostly positive, indicating that neglecting the effect of storage change has resulted in underestimating the elasticities due to precipitation in most of the watersheds. This underestimation appears to be more significant in the western part of the USA. In the central and northeastern USA, the differences hover slightly above zero indicating not much change in elasticity in those regions. The violin plot on the right side also shows that the majority of the basins have under- 


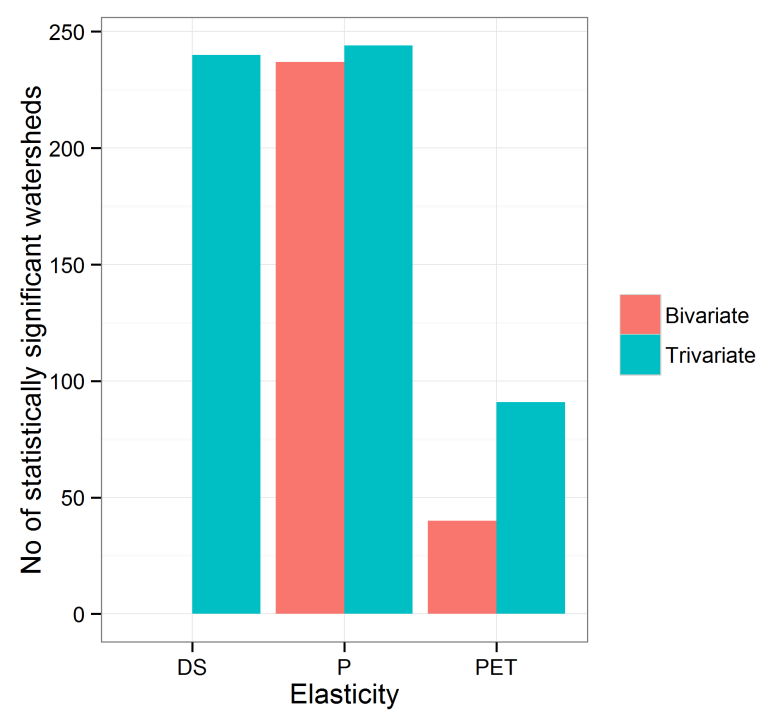

Figure 4. Number of statistically significant watersheds $(p<0.1)$ for the elasticities of bivariate and trivariate equations.

estimated elasticities due to precipitation. The changes in streamflow elasticities due to PET are not shown here because there is less overlap between statistically significant watersheds of trivariate and bivariate equations.

\subsection{Annual streamflow elasticities due to storage change}

Figure 6 illustrates the spatial distribution (left side) of streamflow elasticity due to the addition of storage change whereas the violin plot (right side) shows the probability distribution of streamflow elasticities due to storage change. These values suggest that groundwater has a net negative effect on the streamflow indicating that at an annual scale, a notable amount of water is being stored either as groundwater or as surface water. We can see that in the central and northeastern parts of the USA, the elasticity values are in the range from 0 to -1 . Nevertheless, as we go further west, we can see that the elasticity is decreasing below -1 . It was observed that the high elasticity values are more prevalent in the western USA, which has also caused the significant difference in streamflow elasticity due to precipitation. This indicates that in those regions the change in storage plays an important role in streamflow variability at an annual scale and neglecting these changes would result in improper assessment of streamflow elasticities.

Overall, the low values of streamflow elasticities due to PET highlighted the fact that PET plays a lesser role in influencing the annual streamflow (Zhao et al., 2009, 2010; Wang et al., 2014). Also, there is a lesser number of statistically significant streamflow elasticities due to PET. HHowever, lower PET would result in higher precipitation elasticity (Fu et al., 2007). In addition to that, we observed that the modified elasticity model clearly strengthens the interrelationship between precipitation, potential evapotranspiration, streamflow, and storage changes. This would eventually point to a prominent role of storage changes in the generation of streamflow at annual scales as concluded in other studies (Wang et al., 2009; Miguez-Macho and Fan, 2012; Huntington and Niswonger, 2012). Hence, neglecting these changes would result in either underestimation or overestimation of precipitation and PET elasticities. Moreover, in the situation where $\mathrm{DS}=0$, we can always go back to Eq. (2) which neglects the effect of DS on annual streamflow. However, even though the trivariate elasticity model performs better than the bivariate model, we can see that DS is calculated as a residual (P-Q-AET) and likely to be plagued by uncertainties due to usage of data from different sources and bias does exist. Thus, this may result in improper assessment of storage change. Hence, until more information with decreased uncertainty in the data sources is obtained, this can be viewed as a hypothesis that remains to be tested.

\subsection{Spatial distribution of seasonal streamflow elasticities}

\subsubsection{Streamflow elasticities due to precipitation}

Figure 7 illustrates the seasonal (i.e., fall, spring, summer, and winter) pattern of elasticities derived based on the precipitation. It is observed that, in the fall season, higher elasticity values were observed for watersheds located in the humid north central and northeastern USA, but as the season transformed to winter, these regions had lesser elasticity values compared to other regions. Whereas during spring some of the watersheds located in north central region seem to recover their lost elasticity. Finally, in summer the eastern part of the USA also regains its elasticity. We can see that the snow-dominated western part of the USA does not follow the same cycle as the humid eastern region. There appears to be a lag in the response of streamflow to rainfall with the high elasticity values starting in winter in the western part of the USA. However, it also appears to follow a cycle similar to what we have seen in the eastern part of the USA. This clearly highlights the differential behavior of western and eastern USA streamflow elasticities due to precipitation.

\subsubsection{Seasonal streamflow elasticities due to potential evapotranspiration}

Figure 7 highlights the seasonal pattern of streamflow elasticities due to evapotranspiration. It can be seen that there are comparatively less watersheds that have statistically significant elasticities due to potential evapotranspiration. Higher numbers of statistically significant watersheds were observed during spring followed by winter, summer, and fall. We can see that during fall, the eastern region has a negative elasticity indicating a decrease in streamflow due to an increase 

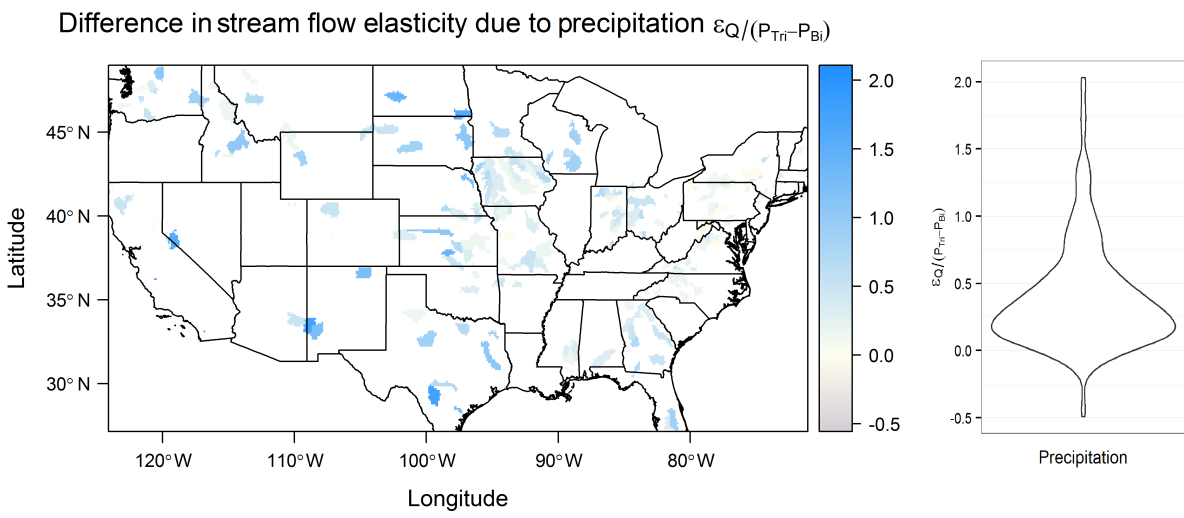

Figure 5. The difference between trivariate and bivariate precipitation elasticities (dimensionless). On the right side, a violin plot shows the distribution of these differences.

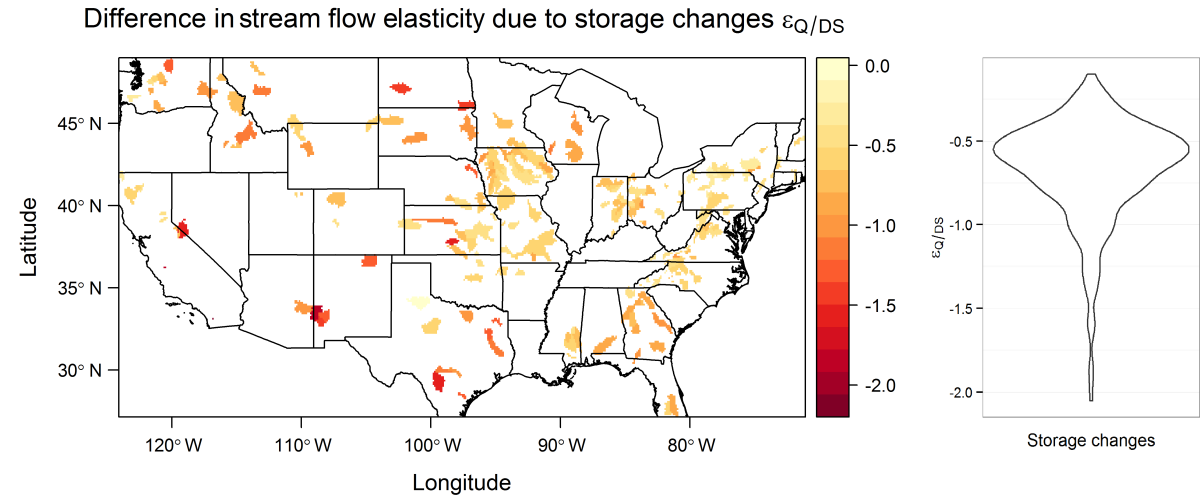

Figure 6. Annual streamflow elasticity due to change in storage (dimensionless) as derived from trivariate equation. On the left side, a violin plot shows the distribution of elasticity due to storage change.

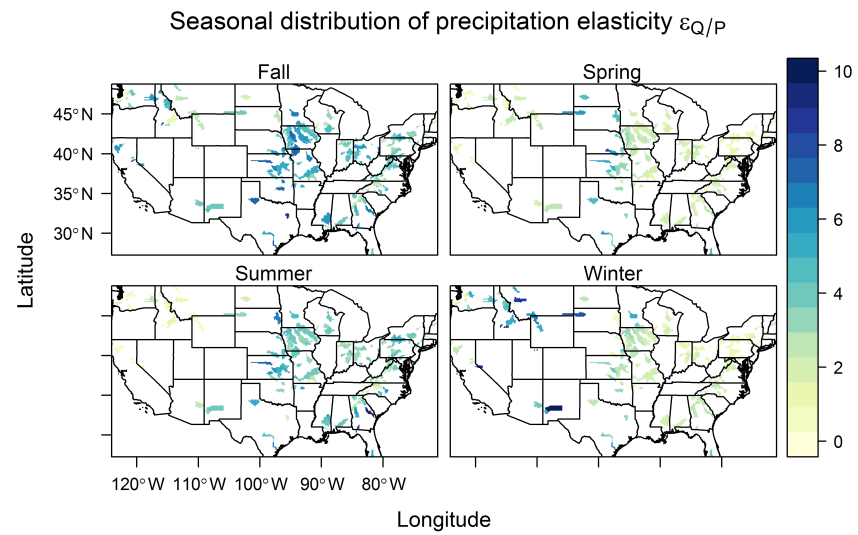

Figure 7. Seasonal distribution of streamflow elasticity due to precipitation (dimensionless).

in potential evapotranspiration. However, in the southwestern watersheds we can see a positive elasticity value indicating an increase in streamflow due to potential evapotranspiration. In previous studies, certain catchments have shown positive streamflow elasticities due to potential evapotran- spiration (Andréassian et al., 2015; Yang et al., 2014). The positive PET elasticity may be caused by the local climate feedback. For example, based on previous studies (Koster et al. 2004; Guo et al., 2006; Mei and Wang, 2012), the central USA has strong land-atmosphere coupling strength. The PET plays an important role in the linkage of soil moisture and precipitation in the land-atmosphere interactions. Based on the positive land-atmosphere interactions, the increased soil moisture would lead to a cascading effect of increase of temperature (indirectly PET) and precipitation. The increased precipitation would therefore lead to the increase of streamflow. In this notation, the PET has a positive relationship with precipitation, which would lead to a positive PET elasticity. The positive PET elasticities are within these hotspots in the summer season. Similarly, in summer the central USA exhibits positive elasticity values whereas the northeastern USA exhibits negative elasticity. During spring most of the watersheds exhibit negative elasticity and the higher magnitudes were observed for the central part of the US. 

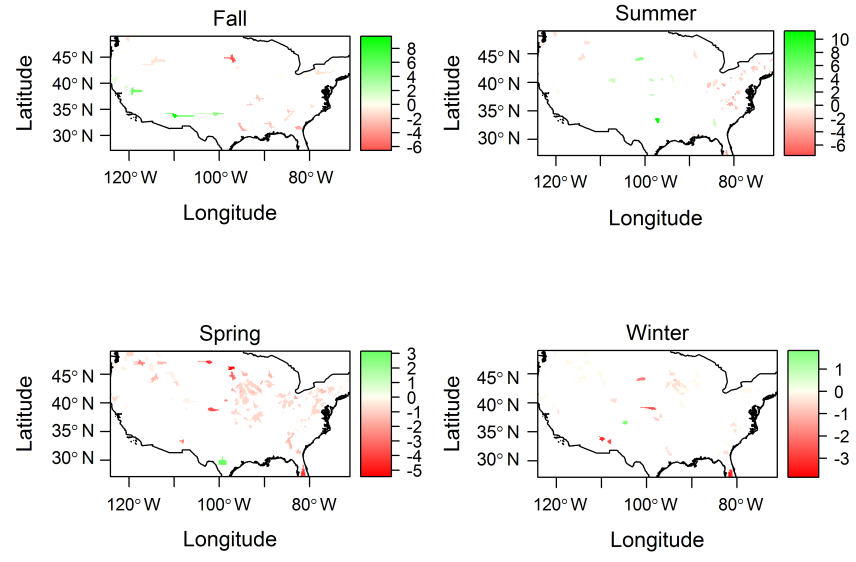

Figure 8. Seasonal distribution of streamflow elasticity due to PET (dimensionless).

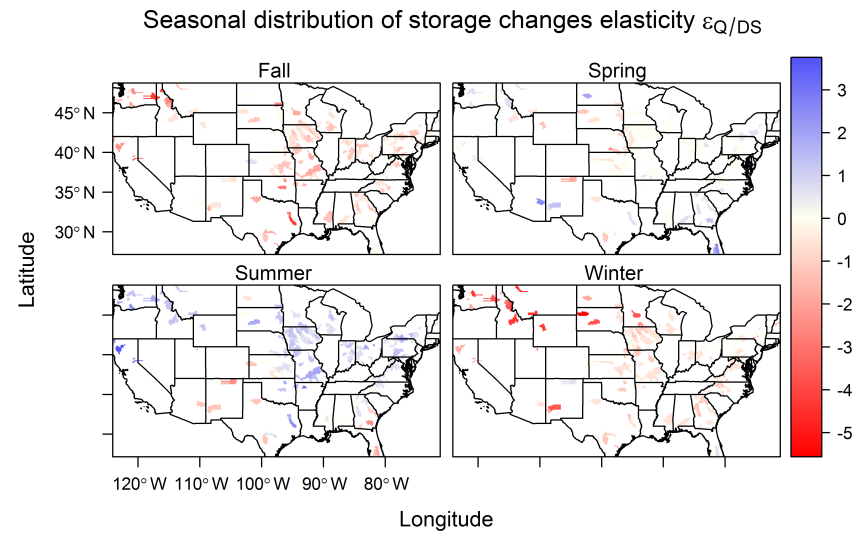

Figure 9. Seasonal distribution of streamflow elasticity due to storage change (dimensionless).

\subsubsection{Seasonal streamflow elasticities due to storage change}

Figure 8 illustrates the seasonal pattern of streamflow elasticities due to storage change. It was observed that the seasonal elasticities exhibit change in spatial clusters. For example, the eastern USA seems to exhibit a cycle of negative elasticities in fall, then its intensity decreases in winter, becomes almost negligible in spring, and exhibits positive elasticity in summer. However, the watersheds on the southeastern coast seem to exhibit negative elasticities in summer followed by a decrease in negative elasticity values in fall and winter. This region exhibits positive elasticity values in spring whereas the rest of the eastern USA exhibits positive elasticity in later seasons. Similarly, in the case of the western USA, it exhibits a cycle of negative elasticity values starting in winter, followed by its decrease in spring, transforms into positive elasticity values during the summer season, and again goes back to negative values in fall. Hence, we can see that the southeastern region has a seasonal cycle that leads the eastern re-

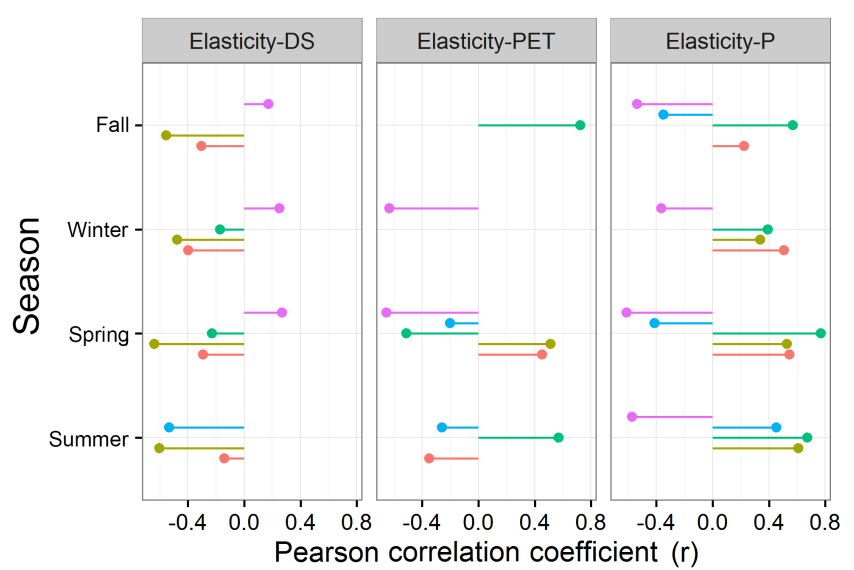

AI $\$$ DS $\phi$ EI $\$ P$ P $Q$

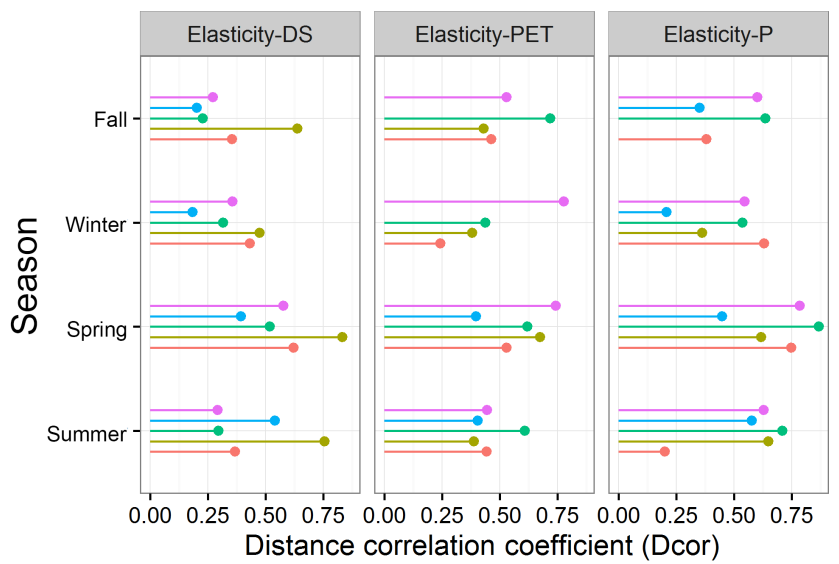

$$
\phi \text { AI } \phi \text { DS } \phi \text { EI } \phi P \text { Q } Q
$$

Figure 10. The linear and nonlinear association strengths as determined by Pearson and distance correlation coefficients. (Note: in the figure, we have sorted the strength of association separately for each season and the hydroclimatic variables are represented by different colors and only statistically significant $(p<0.05)$ correlation strengths are shown here.)

gion by a season, whereas the western USA lags behind the eastern region. During summer, the streamflow is extremely low, whereas precipitation is high. Also, the evapotranspiration does not seem to be completely out of bounds. Hence, we assumed that most of the rainfall is either evaporating or being converted into soil water storage. However, we do acknowledge the fact that the streamflow in those catchments is influenced by storage facilities (Wang and Hejazhi, 2011). The positive elasticity values indicate that for particular seasons, there is an increase in water storage resulting in an increase in runoff. This is mainly because, for that season, the streamflow is contributed by the storage sources in addition to precipitation. Similarly, the negative elasticity values for a particular season indicate that streamflow is withdrawn by the storage sources indicating an inverse relationship. 
Overall, as previously put forth by numerous studies in the case of annual water balances, precipitation has higher elasticity values when compared to both PET and storage changes even at seasonal scale. Considerable seasonality of rainfall elasticity is observed in most of the MOPEX basins in the USA. However, the catchments in the eastern USA exhibit contrasting features of less rainfall seasonality but more streamflow seasonality (Supplement figures). This suggests a prominent role of DS, AET, and PET in streamflow seasonality since human influence is considered minimal in the eastern region (Wang and Hejazi, 2011). Another important observation is the lag time exhibited by the catchments in the western USA in terms of precipitation elasticity. There appears to be a precipitation plus snowfall excess during fall and streamflow excess during spring, whereas during winter, the precipitation plus snowmelt is in phase with streamflow during winter (Berghuilius, 2014). This might be the reason for the high elasticities during winter. However, this result should be interpreted with caution, since the western USA has significant human-induced streamflow changes (Wang and Hejazi, 2011). Also, the storage changes have shown considerable seasonal elasticity values. The seasonal DS elasticities indicate that soils act as a natural reservoir and subsequently supply and store the streamflow during various seasons. For example, during the higher water demand in summer, the groundwater (storage) supplies water to the streamflow resulting in a positive elasticity in most of the MOPEX basins, whereas during winter and spring, the soil gets recharged and that leads to negative elasticity values. However, we observed that in the western USA, the negative elasticity magnitude peaks during winter unlike the rest of US MOPEX basins. This may be mainly because groundwater contribution to streamflow is inversely correlated to snowmelt runoff (Huntington and Niswonger, 2012). Hence, it possibly has high negative elasticity values when the snow accumulates in winter, whereas when the snowmelt runoff starts in the spring, it starts contributing to streamflow indicating positive elasticities.

\subsection{Relationship between elasticity and hydroclimatic characteristics of the catchments}

This analysis allows for a quantitative investigation of relations between the seasonal elasticities and catchment climate properties and gives an understanding of the possible governing factors. Figure 10 shows the statistically significant linear (top panel) and nonlinear correlations (bottom panel) between the considered seasonal hydroclimatic variables and elasticities. We excluded high elasticity values greater than 10 and less than -5 in this analysis which may be unrealistic due to uncertainty in the data sources by visual examination of the scatterplots provided in the Supplement. As we expected, there does exist significant nonlinear associations between elasticities and considered catchment properties. Hence, we base most of our discussions in this text on the nonlinear associations presented in the figure, but sometimes refer the linear association for determining the directionality of the relationships.

It is interesting to see how the hydroclimatic variables' relationship changes with each season. For example, during summer there exists a stronger association of rainfall magnitude and less predominant association of streamflow with elasticities than in other seasons. During summer, due to relatively high temperatures and inadequacy of available water as streamflow, the catchments become water limited leading them to be more dependent on rainfall as a source of water. This behavior is more prevalent in storage changes elasticity. Also, it is obvious that the elasticities are more governed by the magnitudes of streamflow in most of the other cases. However, the linear associations suggest that the streamflow is inversely proportional to precipitation and potential evapotranspiration elasticities. Usually, if the catchments with high streamflow are highly elastic in nature, even a minimal amount of rainfall would result in high streamflow generation, which might impact existing flood and water management activities. Hence, this inverse relationship which is achieved either through artificial or natural storage facilities is beneficial to water management. In the case of elasticity due to storage change, when the elasticities have negative values (in fall and winter), there exists a positive linear relationship with streamflow achieving a similar goal of efficient water management. However, we suspect that this might not be a natural behavior of a catchment as significant human interference might have created this behavior (Wang and Hezaidi, 2011; Ye et al., 2014). Also, there exists a significant inter-relationship between the hydroclimatic variables and determined elasticities. For example, the seasonal magnitude of DS affects PET elasticity as well as precipitation elasticity in most of the seasons. The same conclusion can be reached in other cases too.

The aridity index (AI), which is a possible indicator of catchment and climate (the higher the aridity index, the drier the catchment) (Jones et al., 2012) also has a significant association with climate elasticities. The negative correlations between AI and DS elasticities indicate that the dry catchments have higher DS elasticities. Hence, drier catchments have the capacity to store streamflow during wet seasons and aid in streamflow generation during dry seasons. This study could further help in investigating the discharge and recharge mechanisms of the available MOPEX basins. Similarly, interpretations can be made in terms of precipitation elasticity for positive correlations. In addition to that, AI plays a more significant role in the spring season, indicating that the elasticities are more susceptible to catchment (climate) conditions in that season. Similarly, the evaporative index, which is an indirect gauge of the physical properties of catchments (Jones et al., 2012), has significant associations as well as higher magnitude in the spring season. This analysis complements many studies which have linked the catchment properties at different scales to streamflow dynamics (Chiverton 
et al., 2015; Van Loon and Laaha, 2015; Gaál et al., 2012; Ye et al., 2015). However, we do not want to stress a single dominant factor affecting the streamflow elasticities, since there appears to be a strong interplay between elasticities and all the considered catchment properties with substantial seasonal variations.

\section{Summary and conclusions}

a. The proposed three-parameter streamflow elasticity model can be a better model than the two-parameter elasticity model as it underestimated the streamflow elasticity due to precipitation. This is because the threeparameter model was able to account for the covariation of precipitation, potential evaporation, and storage change.

b. Seasonality plays a prominent role in streamflow elasticities with more complex behavior in western USA basins. This complex behavior may be linked to snow cover in the selected western basins. However, a dedicated study in this direction could further strengthen this hypothesis.

c. The streamflow elasticities show significant nonlinear associations with the MOPEX catchment properties. However, we do not want to stress any single dominant factor affecting the streamflow elasticities, since there appears to be a strong interplay between elasticities and catchment properties with substantial seasonal variations.

d. We have tested our hypothesis based on the assumption of significant deep groundwater losses at annual and seasonal scales. However, due to shortage of actual evapotranspiration data sets, there may be uncertainties in the results and it can be improved by evaluating highquality observations. This can be viewed as a hypothesis that remains to be tested using high-quality climate data as and when available.

\section{The Supplement related to this article is available online at doi:10.5194/hess-20-2545-2016-supplement.}

Acknowledgements. Authors are very thankful to Dingbao Wang for his valuable discussion and sharing the data for preparing the manuscript. We are also thankful to Hongyi Li for his encouragement to submit our manuscript to this special issue. We would like to thank W. R. Berghuilius, M. C. Westoff, and the anonymous reviewer for their constructive comments which helped us in preparing our manuscript.

Edited by: H. Li

\section{References}

Akaike, H.: Information theory and an extension of the maximum likelihood principle, in: Selected Papers of Hirotugu Akaike, Springer, 199-213, 1998.

Andréassian, V., Coron, L., Lerat, J., and Le Moine, N.: Climate elasticity of streamflow revisited - an elasticity index based on long-term hydrometeorological records, Hydrol. Earth Syst. Sci. Discuss., 12, 3645-3679, doi:10.5194/hessd-12-3645-2015, 2015.

Arora, V. K.: The use of the aridity index to assess climate change effect on annual runoff, J. Hydrol., 265, 164-177, 2002.

Atkinson, S., Woods, R., and Sivapalan, M.: Climate and landscape controls on water balance model complexity over changing timescales, Water Resour. Res., 38, 50-1-50-17, 2002.

Berghuijs, W. R., Sivapalan, M., Woods, R. A., and Savenije, H. H.: Patterns of similarity of seasonal water balances: A window into streamflow variability over a range of time scales, Water Resour. Res., 50, 5638-5661, 2014.

Berghuijs, W. R., Hartmann, A., and Woods, R. A.: Streamflow sensitivity to water storage changes across Europe, Geophys. Res. Lett., 43, 1980-1987, 2016.

Budyko, M. I.: The heat balance of the earth's surface, Soviet Geogr., 2, 3-13, 1961.

Chen, X., Alimohammadi, N., and Wang, D.: Modeling interannual variability of seasonal evaporation and storage change based on the extended Budyko framework, Water Resour. Res., 49, 60676078, 2013.

Chiew, F. H.: Estimation of rainfall elasticity of streamflow in Australia, Hydrol. Sci. J., 51, 613-625, 2006.

Chiverton, A., Hannaford, J., Holman, I., Corstanje, R., Prudhomme, C., Bloomfield, J., and Hess, T. M.: Which catchment characteristics control the temporal dependence structure of daily river flows?, Hydrol. Process., 29, 1353-1369, 2015.

Cover, T. M. and Thomas, J. A.: Information theory and statistics, Elements of Information Theory, 279-335, 1991.

Dooge, J. C.: Sensitivity of runoff to climate change: A Hortonian approach, B. Am. Meteor. Soc., 73, 2013-2024, 1992.

Farmer, D., Sivapalan, M. and Jothityangkoon, C.: Climate, soil, and vegetation controls upon the variability of water balance in temperate and semiarid landscapes: Downward approach to water balance analysis, Water Resour. Res., 39, 2003.

Fu, G., Charles, S. P., and Chiew, F. H.: A two-parameter climate elasticity of streamflow index to assess climate change effects on annual streamflow, Water Resour. Res., 43, W11419, doi:10.1029/2007WR005890, 2007.

Gaál, L., Szolgay, J., Kohnová, S., Parajka, J., Merz, R., Viglione, A., and Blöschl, G.: Flood timescales: Understanding the interplay of climate and catchment processes through comparative hydrology, Water Resour. Res., 48, W04511, doi:10.1029/2011WR011509, 2012.

Greene, W. H.: The econometric approach to efficiency analysis, The measurement of productive efficiency and productivity growth, 42, 92-250, 2008.

Guo, H., Hu, Q., and Jiang, T.: Annual and seasonal streamflow responses to climate and land-cover changes in the Poyang Lake basin, China, J. Hydrol., 355, 106-122, 2008.

Guo, Z., Dirmeyer, P. A., Koster, R. D., Sud, Y., Bonan, G., Oleson, K. W., Chan, E., Verseghy, D., Cox, P., and Gordon, C.: GLACE: 
the global land-atmosphere coupling experiment, Part II: analysis, J. Hydrometeorol., 7, 611-625, 2006.

Harris, I., Jones, P., Osborn, T., and Lister, D.: Updated highresolution grids of monthly climatic observations-the CRU TS3, doi:10 Dataset, Int. J. Climatol., 34, 623-642, 2014.

Helsel, D. R. and Hirsch, R. M.: Statistical methods in water resources, Elsevier, 340-364, 1992.

Hoeffding, W.: A non-parametric test of independence, Ann. Math. Stat., 23, 546-557, 1948.

Huntington, J. L. and Niswonger, R. G.: Role of surface-water and groundwater interactions on projected summertime streamflow in snow dominated regions: An integrated modeling approach, Water Resour. Res., 48, W11524, doi:10.1029/2012WR012319, 2012.

Istanbulluoglu, E., Wang, T., Wright, O. M., and Lenters, J. D.: Interpretation of hydrologic trends from a water balance perspective: The role of groundwater storage in the Budyko hypothesis, Water Resour. Res., 48, 2012.

Jiang, C., Xiong, L., Wang, D., Liu, P., Guo, S., and Xu, C.: Separating the impacts of climate change and human activities on runoff using the Budyko-type equations with time-varying parameters, J. Hydrol., 522, 326-338, 2015.

Johnston, J. and DiNardo, J.: Econometric methods, Cambridge University Press, 456-487, 1997.

Jones, J. A., Creed, I. F., Hatcher, K. L., Warren, R. J., Adams, M. B., Benson, M. H., Boose, E., Brown, W. A., Campbell, J. L., and Covich, A.: Ecosystem processes and human influences regulate streamflow response to climate change at long-term ecological research sites, Bioscience, 62, 390-404, 2012.

Kinney, J. B. and Atwal, G. S.: Equitability, mutual information, and the maximal information coefficient, P. Natl. Acad. Sci. USA, 111, 3354-3359, doi:10.1073/pnas.1309933111, 2014.

Koster, R. D., Dirmeyer, P. A., Guo, Z., Bonan, G., Chan, E., Cox, P., Gordon, C. T., Kanae, S., Kowalczyk, E., Lawrence, D., Liu, P., Lu, C. H., Malyshev, S., McAvaney, B., Mitchell, K., Mocko, D., Oki, T., Oleson, K., Pitman, A., Sud, Y. C., Taylor, C. M., Verseghy, D., Vasic, R., Xue, Y., Yamada, T., and GLACE Team: Regions of strong coupling between soil moisture and precipitation, Science, 305, 1138-1140, doi:10.1126/science.1100217, 2004.

Mei, R. and Wang, G.: Summer land-atmosphere coupling strength in the United States: comparison among observations, reanalysis data, and numerical models, J. Hydrometeorol., 13, 1010-1022, 2012.

Miguez-Macho, G. and Fan, Y.: The role of groundwater in the Amazon water cycle: 1 . Influence on seasonal streamflow, flooding and wetlands, J. Geophys. Res.-Atmos., 117, 2012.

Němec, J. and Schaake, J.: Sensitivity of water resource systems to climate variation, Hydrol. Sci. J., 27, 327-343, 1982.

Niemann, J. D. and Eltahir, E. A.: Sensitivity of regional hydrology to climate changes, with application to the Illinois River basin, Water Resour. Res., 41, W07014, doi:10.1029/2004WR003893, 2005

Ol'Dekop, E.: On evaporation from the surface of river basins, Transactions on meteorological observations, 4, 1911.

Pike, J.: The estimation of annual run-off from meteorological data in a tropical climate, J. Hydrol., 2, 116-123, 1964.

Potter, N., Petheram, C., and Zhang, L.: Sensitivity of streamflow to rainfall and temperature in south-eastern Australia during the
Millennium drought, in: 19th International Congress on Modelling and Simulation, Perth, December 2011.

Reshef, D. N., Reshef, Y. A., Finucane, H. K., Grossman, S. R., McVean, G., Turnbaugh, P. J., Lander, E. S., Mitzenmacher, M., and Sabeti, P. C.: Detecting novel associations in large data sets, Science, 334, 1518-1524, doi:10.1126/science.1205438, 2011.

Roderick, M. L., Rotstayn, L. D., Farquhar, G. D., and Hobbins, M. T.: On the attribution of changing pan evaporation, Geophys. Res. Lett., 34, L17403, doi:10.1029/2007GL031166, 2007.

Sankarasubramanian, A., Vogel, R. M., and Limbrunner, J. F.: Climate elasticity of streamflow in the United States, Water Resour. Res., 37, 1771-1781, 2001.

Schaake, J., Cong, S., and Duan, Q.: The US MOPEX data set, IAHS publication, 307, 9-28, 2006.

Schreiber, P.: Über die Beziehungen zwischen dem Niederschlag und der Wasserführung der Flüsse in Mitteleuropa, Z. Meteorol., 21, 441-452, 1904.

Schwarz, G.: Estimating the dimension of a model, The annals of statistics, 6, 461-464, 1978.

Székely, G. J. and Rizzo, M. L.: Brownian distance covariance, Ann. Appl. Stat., 3, 1236-1265, 2009.

Tomer, M. D. and Schilling, K. E.: A simple approach to distinguish land-use and climate-change effects on watershed hydrology, J. Hydrol., 376, 24-33, 2009.

Turc, L.: Le bilan d'eau des sols: relations entre les précipitations, l'évaporation et l'écoulement, Institute National de la Recherche Agronomique, 5, 491-569, 1953.

Van Loon, A. and Laaha, G.: Hydrological drought severity explained by climate and catchment characteristics, J. Hydrol., 526, 3-14, 2015.

Vano, J. A., Nijssen, B., and Lettenmaier, D. P.: Seasonal hydrologic responses to climate change in the Pacific Northwest, Water Resour. Res., 51, 1959-1976, 2015.

Wang, D. and Alimohammadi, N.: Responses of annual runoff, evaporation, and storage change to climate variability at the watershed scale, Water Resour. Res., 48, W05546, doi:10.1029/2011WR011444, 2012.

Wang, D. and Hejazi, M.: Quantifying the relative contribution of the climate and direct human impacts on mean annual streamflow in the contiguous United States, Water Resour. Res., 47, W00J12, doi:10.1029/2010WR010283, 2011.

Wang, T., Istanbulluoglu, E., Lenters, J., and Scott, D.: On the role of groundwater and soil texture in the regional water balance: an investigation of the Nebraska Sand Hills, USA, Water Resour. Res., 45, W10413, doi:10.1029/2009WR007733, 2009.

Wang, X.: Advances in separating effects of climate variability and human activity on stream discharge: An overview, Adv. Water Resour., 71, 209-218, 2014.

Yang, H. and Yang, D.: Derivation of climate elasticity of runoff to assess the effects of climate change on annual runoff, Water Resour. Res., 47, W07526, doi:10.1029/2010WR009287, 2011.

Ye, S., Li, H., Li, S., Leung, L. R., Demissie, Y., Ran, Q., and Blöschl, G.: Vegetation regulation on streamflow intra-annual variability through adaption to climate variations, Geophys. Res. Lett., 42, 10307-10315, doi:10.1002/2015GL066396, 2015.

Zhang, K., Kimball, J. S., Nemani, R. R., and Running, S. W.: A continuous satellite-derived global record of land surface evapotranspiration from 1983 to 2006, Water Resour. Res., 46, W09522, doi:10.1029/2009WR008800, 2010. 
Zhang, L., Dawes, W., and Walker, G.: Response of mean annual evapotranspiration to vegetation changes at catchment scale, Water Resour. Res., 37, 701-708, 2001.

Zhao, F., Xu, Z., Zhang, L., and Zuo, D.: Streamflow response to climate variability and human activities in the upper catchment of the Yellow River Basin, Sci. China, 52, 3249-3256, 2009.
Zhao, G., Hörmann, G., Fohrer, N., Zhang, Z., and Zhai, J.: Streamflow trends and climate variability impacts in Poyang Lake Basin, China, Water Resour. Manage., 24, 689-706, 2010. 